\title{
Soto, J. (2008). El currículo intercultural bilingüe. La naturaleza humana integrada a su mundo cultural. Magisterio
}

\author{
The intercultural bilingual curriculum. Human nature integrated to its \\ cultural world
}

Alexander Steffanell ${ }^{1}$ (1)

\section{INTRODUCCIÓN}

Plantear un proyecto neoliberal en los contenidos de textos de enseñanza de lenguas extranjeras parece una tarea muy común en las editoriales de hoy en día. El sistema editorial y publicación de texto establecen un control de la diferencia académica en la implementación de currículos que no buscan cambios o que no representan la cultura donde la lengua extranjera se enseña. Acuñando el término "colonialidad del poder", traído a colación por el investigador argentino Aníbal Quijano en 1990, El currículo intercultural bilingüe, escrito por Jairo Soto Molina, busca un modelo intercultural en oposición al multiculturalismo propiamente dicho. Igualmente, el investigador colombiano esclarece detalladamente desde el pensamiento complejo de Edgar Morin, las inteligencias múltiples de Howard Garner y el enfoque interdisciplinario de Jurgo Torres y Ezequiel AnderEgg "un modelo de educación intercultural para usar el inglés de una manera que se ajuste a sus necesidades y aspiraciones mientras, consecuentemente, se resistan al imperialismo lingüístico" (Soto Molina, 2008, p. 13).

Consecuentemente, una lengua no expresa exclusivamente una cultura, sino que estas relaciones equivocadamente se convierten en unilaterales provocando una falla en el sistema pedagógico. No es erradicar la cultura que reciben sino fortalecerla utilizando el inglés en la enseñanza y teniendo en cuenta lo bilingüe a los grupos étnicos con tradición lingüística propia. Por tanto, el currículo intercultural bilingüe se enfoca principalmente en el rompimiento imperialista de la lengua extranjera que busca una alineación cultural con la lengua impuesta olvidando lo más importante en las culturas habitadas.

1 Lee University. Cleveland, Tennessee (USA).

Correspondencia: Alexander Steffanell. Email: asteffanell@leeuniversity.edu Recibido: 28/04/2021. Aceptado: 28/06/2021.

DOI: 10.26885/rcei.10.1.172

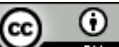
Publicado en acceso abierto bajo Licencia Creative Commons. 


\section{Soto, J (2008). El currículo intercultural bilingüe. La naturaleza humana integrada a su mundo cultural. Magisterio Alexander Steffanell}

El autor Jairo Soto Molina nos trae una información acertada en cuanto a la interculturalidad en el concepto intencional e internacional definida más acertadamente a los desafíos educativos de hoy en los procesos pedagógicos. Igualmente aporta que existen elementos que nutren y que alimentan el currículo intercultural y las teorías sustentadas aportando bases teóricas y conceptos de los elementos del currículo intercultural bilingüe. Se observa, a su vez, la incidencia de una educación intercultural en el desarrollo humano, coincidiendo con una de las principales teorías o afirmaciones del investigador colombiano. Sin embargo, Jairo Soto Molina no olvida la enseñanza del inglés según un enfoque intercultural integrado a la transversalidad del currículo y elabora un trabajo interdisciplinario dentro de una lectura contextual en las diferentes instituciones educativas.

Otra de las contribuciones relevantes del texto de Jairo Solo Molina es la asociación del currículo con evaluaciones estructurales que están haciendo una política educativa en el salón de clase y también a nivel de los ministerios de educación. Es decir, el currículo debe ubicarse en un estado avanzado dentro de la ciudadanía pedagógica e indicar un compromiso de parte del gobierno de las instituciones educativas y de los estudiantes y principalmente de los profesores en una participación y social. Jairo Soto Molina, a través de su texto, promueve habilidades de pensamiento crítico y reflexión en el desarrollo de una comprensión tanto lectora como de escritura en el momento de la enseñanza y la importancia que cumple el maestro dentro de la comunidad local regional nacional y global. Definitivamente estamos ante un texto que contribuye significativamente a tener una cohesión pedagógica dentro del sistema escolar y sobre todo en la estructura curricular en la formación del texto educativo apoyando una comunicación intercultural y una competencia comunicativa en la participación formal del estudiante.

Jairo Soto Molina considera importante la inclusión de un currículo lingüístico a través de contextos que examinan oportunidades y desafíos posteriores a la educación formal en los estudiantes provocando así mismo una cooperación ciudadana y global siempre y cuando no se olvide la cultura de origen.

Por lo tanto, el profesor Jairo Soto Molina propone un currículo intercultural bilingüe integrado a las necesidades de los estudiantes teniendo en cuenta la conciencia lingüística, orientación de contenidos curriculares, orientación colaborativa y actuaciones pertinentes en la integración de estrategias pedagógicas que propendan por la inclusión de parámetros culturales de la lengua/cultura visitada. Existe una dimensión cultural y una panorámica en la exposición descentralizada de una lengua que tenga en cuenta la perspectiva del otro (en nuestro caso) que tiene validez.

Se infiere que el texto de Jairo Soto Molina establece que el currículo intercultural bilingüe se debe observar como una comunidad de aprendizaje 
como agente social, el cual hace la contribución pedagógica en la competencia intercultural. En todo programa curricular intercultural bilingüe la porción del currículo debe ayudar a crear conciencia para transformar la sociedad y existir una interdependencia de su mundo circundante que enfatice el potencial del ser humano para contribuir a la sociedad. En la educación intercultural bilingüe se propende por el respeto de la diversidad de perspectiva representadas a nivel global, y que los estudiantes articulen su propio entendimiento, sus propios valores y cómo estos se relacionan con otras perspectivas culturales. Debe haber un dialogo intercultural con encuentros lingüísticos.

Descentralizar y promover la flexibilidad del currículo intercultural bilingüe integrado es una tarea acuciosa en el texto de Jairo Soto Molina, ya que combina los procesos educativos y pedagógicos con las ideas humanistas de la misma educación y la cultura en oposición a los debates intelectuales que cierran posibilidades emancipadoras y liberadoras. Soto Molina evoca a Lemke (1988) en cuando que el currículo debe ser "reductor de desigualdades sociales, compensatorio, participativo, integrador, integral, formativo, creativo, permanente, relevante, flexible y orientado hacia el trabajo (citado en Soto Molina, 2008, pp. 42-43). Igualmente, Soto Molina construye una teoría pedagógica con los aportes de Magendzo (1991) pues establece que "el currículo es una actividad compartida por los miembros de una comunidad educativa donde se establecen ritmos de socialización y de integración comunitaria, donde se le da un valor a la cotidianidad como eje transformador de la cultura y el mejoramiento de las condiciones de vida de una comunidad para que alcance su pleno desarrollo" (citado en Soto Molina, 2008, p. 43).

Gran parte de la responsabilidad de la enseñanza de las lenguas extranjeras recae sobre la decisión del maestro en el aula de clases. El maestro es el encargado de elegir temáticas contenidos, "qué enseñar, por qué enseñar, cuándo enseñarlo, e incluso cómo enseñarlo suponen unos juicios de valor. Estas decisiones son juicios de valor que pueden tener consecuencias o exitosas o desastrosas" (Soto Molina, 2008, p. 63). Es el maestro quien debe proponer deliberada y explícitamente compromisos pedagógicos para el aprendiz y traer encuentros interculturales. El maestro de lengua extranjera ofrece habilidades para el entendimiento e interpretación de experiencias que transformen los procesos del aula de clases y que tengan un aprendizaje reflexivo y crítico. Además de los aportes pedagógicos que El currículo intercultural bilingüe ofrece a la comunidad educativa, creo que el texto fortalece los desafíos éticos en la competencia intercultural en la formación del estudiante de lengua extranjera. Para el maestro de lenguas, se hace indispensable la formación de la percepción de la realidad en el estudiante lo que conllevaría a transformar el nivel de compromiso de este con su ciudadanía global. Las relaciones basadas en una pedagogía intercultural bilingüe se enlazan con factores que elucidan el pensamiento complejo, propuesto por Morin, y basan la experiencia en 


\section{Soto, J (2008). El currículo intercultural bilingüe. La naturaleza humana integrada a su mundo cultural. Magisterio Alexander Steffanell}

proyecto que apuntalen a promover competencias interculturales dentro de un currículo flexible. Lo anterior, por supuesto, no solamente debe tocar destrezas comunicativas tales como escuchar, hablar, leer y escribir, sino también "la estrecha relación que se establece entre la clase de lengua y las de las demás áreas, hasta el punto en que el aprendizaje y la enseñanza no se presentan necesariamente en lecciones individuales por áreas o asignaturas diferentes sino que se integran en temas que se desarrollan de manera activa, generalmente a través de actividades (tareas) y proyectos investigativos llevados a cabo por los estudiantes" (Soto Molina, 2008, p. 115).

Siguiendo con la anterior línea de pensamiento, y apoyado en el movimiento pedagógico surgido en loa Estados Unidos en la década de los 80, Jairo Soto Molina se apresta a la integralidad del currículo donde la comunicación ejerce un papel preponderante para el desarrollo del conocimiento global sin interferir en la producción local de su propio entendimiento cultural de los pueblos. Con este proyecto lingüístico y cultural, además de la brillante propuesta de este nuevo texto de enseñanza de lengua extranjera, el presente investigador colombiano determina factores para el destino acertado de sus aprendices: no hay rompimiento entre las culturas, sino más bien una integración sociolingüística que rompe paradigmas tradicionales y no estigmatiza la cultura a la que nos aproximamos. El texto en cuestión contribuye como tal con la integración de proyectos comunitarios que se enfocan en la adopción de posiciones positivas y de avanzada donde el valor pedagógico coadyuve con la identidad cultural en condiciones de igualdad.

Por último, y no menos importante, Jairo Soto Molina (2008) crea talleres, rúbricas y lineamientos generales en planillas o unidades de aprendizaje sugiriendo como punto estratégico la integración curricular interdisciplinar. En dichas planillas el estudiante debe identificar ambientes comunicativos, interés lingüístico y cultural, temáticas que contribuyan a su propio pensamiento crítico, y las diferentes condiciones de impacto entre la enseñanza y el aprendizaje (pp. 140-141). Asimismo, el texto es un aporte significativo para un proceso curricular flexible que provea lecciones diarias de planeación, guías que promulguen por la interdisciplinariedad curricular y la formación de docentes abiertos y dispuestos a afrontar aprendizajes profundos, experimentales y ajustados a la realidad circundante.

El libro El currículo intercultural bilingüe (2008), escrito por el profesor Jairo Soto Molina y publicado por Magisterio, es pionero en la historiografía de los estudios interculturales bilingües en Colombia y hoy en día se ha convertido en un locus de diálogo para los nuevos investigadores, conversaciones que suscitan acuerdos y progresos en la plataforma de los sistemas educativas tanto en Colombia como en Latinoamérica en general. Es interesante cómo este texto, aún hoy en el año 2021, a doce años de su publicación original, todavía "levanta polvorín" en medio del debate educativo de la enseñanza de las 
lenguas extranjeras. Es un texto específico para profesores de lengua extranjera, estudios interculturales, estudiantes de licenciatura en lenguas, investigadores y lingüistas que quieren encontrar significados relevantes a los procesos pedagógicos con transformación social. El currículo intercultural bilingüe arrastra una carga interaccional donde los protagonistas son los estudiantes e igualmente apoya fielmente la diversidad, el pluralismo, la creatividad humana, la libre experimentación, la multiplicidad de unidades académicas que se adscriben a ciertas didácticas que fortalecen conciencias y comportamientos de cambio. Graduado en Filología y Letras de la Universidad del Atlántico, con estudios de posgrado en la Universidad de California en San Diego, experto en la enseñanza del inglés como lengua extranjera, y doctor en ciencias humana de la Universidad de Zulia, el profesor investigador Jairo Eduardo Soto Molina irrumpe con su texto en la perentoria discusión de la enseñanza intercultural bilingüe, con un compromiso genuino en los cambios sociales y pedagógicos, consecuente con el discurso educativo de hoy en día. Desde su lugar de enunciación y su posición como docente universitario e investigador meritorio, Jairo Eduardo Soto Molina contribuye con la intelectualidad colombiana y latinoamericana a través de su texto enriquecido de su vasta experiencia como docente investigador de la Universidad del Atlántico. Cabe decir que el trabajo del profesor Jairo Soto Molina ha sido minucioso, detallado, con una óptica social y un compromiso en las altas esferas de la educación, pero que contempla un pensamiento canalizado hacia el futuro de la educación colombiana.

\section{Referencia}

Soto Molina, J. (2008). El currículo intercultural bilingüe. Magisterio.

\section{SOBRE EL AUTOR}

Alexander Steffanell, PhD is Professor of Spanish. Latin American Studies Director. Language and Literature Department. Lee University, Cleveland, Tennessee (USA).

\section{COMO CITAR}

Steffanell, A. (2021). Soto, J. (2008). El currículo intercultural bilingüe. La naturaleza humana integrada a su mundo cultural. Magisterio. Rev. cient. estud. investig., 10(1), 172-176. https://doi.org/10.26885/ rcei.10.1.172 